\title{
Storming the Bastille: the effect of electric fields on the ionospheric F-layer
}

\author{
H. Rishbeth ${ }^{1, \dagger}$, R. A. Heelis ${ }^{2}$, J. J. Makela ${ }^{3}$, and S. Basu ${ }^{4}$ \\ ${ }^{1}$ School of Physics and Astronomy, University of Southampton, Southampton, UK \\ ${ }^{2}$ William B. Hanson Center for Space Sciences, The University of Texas at Dallas, Richardson, TX, USA \\ ${ }^{3}$ Department of Electrical and Computer Engineering, University of Illinois at Urbana-Champaign, Urbana, IL 61801, USA \\ ${ }^{4}$ Institute for Scientific Research, Boston College, Chestnut Hill, MA, USA \\ $\dagger$ deceased
}

Received: 11 March 2010 - Accepted: 6 April 2010 - Published: 16 April 2010

\begin{abstract}
We discuss different phenomena occurring during ionospheric F-region storms that in principle might be caused by electric fields and point out challenges that must be faced when considering the physical processes at work. We consider the transport of plasma across many degrees of latitude at sub-auroral latitudes, the origin of patches of socalled "storm enhanced density" at high mid-latitudes, and the very high reported heights of the F2 peak at low latitudes. We discuss the role that electric fields might play in changing locally the net production of ionization as well as transporting it. We suggest that the local change in ionization production should be considered as a more important process for producing plasma density enhancements than transport from a more remote source of enhanced density.
\end{abstract}

Keywords. Ionosphere (Ionization mechanisms; Midlatitude ionosphere; Modeling and forecasting)

\section{Introduction}

During geomagnetic "superstorms", significant enhancements in the total electron content (TEC) appear at middle latitudes across local noon and into the evening sector and may be imaged in the equatorial plane. A good illustration is provided by the "Bastille storm", so named because the associated solar flare occurred on the eponymous day 211 years later, 14 July 2000, though the ionospheric storm was on St Swithin's day, 15 July. Several papers on this event have been published, for example Basu et al. (2001) and Kil

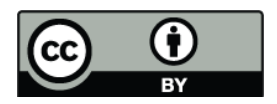

Correspondence to: R. A. Heelis (heelis@utdallas.edu) et al. (2003) and, on other such large events (Foster et al., 2004; Lin et al., 2005; Immel et al., 2005).

In Fig. 1 the left panel is a GPS map of ionospheric TEC, averaged over 22:00-24:00 UT and centered at longitude $90^{\circ} \mathrm{W}$. It therefore covers an 8-h period in local time centered at 17:00 on 15 July 2000 (day 197). It may be contrasted with the right panel showing a similar map for a more usual day, 9 July 2000 (day 191). The spatial continuity of the storm TEC enhancement is limited by the distribution of GPS receivers, but a 3-fold enhancement across the afternoon and early evening sectors in North and South America is clearly seen. During the Bastille storm and other so-called superstorms, enhancements in the upward ion drifts are seen near the magnetic equator and attributed to electrodynamic drift (often called $\boldsymbol{E} \times \boldsymbol{B}$ drift) resulting from the "penetration" of electric fields from high latitudes. Storm perturbations in the vertical ion drift are generally upward during the daytime and downward at night (Scherliess and Fejer, 1999). Large upward drift perturbations also occur near sunset (Heelis and Coley, 2007).

Mannucci et al. (2005) have shown that, in response to these drifts, storm TEC enhancements occur across the dayside ionosphere at low and middle latitudes, and Tsurutani et al. (2004) describe a so-called super-fountain effect that creates a poleward displacement of the equatorial anomaly peaks in the presence of enhanced outward meridional $\boldsymbol{E} \times \boldsymbol{B}$ drifts (Yin et al., 2004). The large drift perturbations near sunset, which also require discussion, can raise the $\mathrm{F}$ peak to heights above $800 \mathrm{~km}$ (Basu et al., 2007) and produce anomalously large TEC at magnetic latitudes beyond 30 degrees. These same uplifts are responsible for post-sunset spread-F structures and the appearance of intense radio scintillation. 

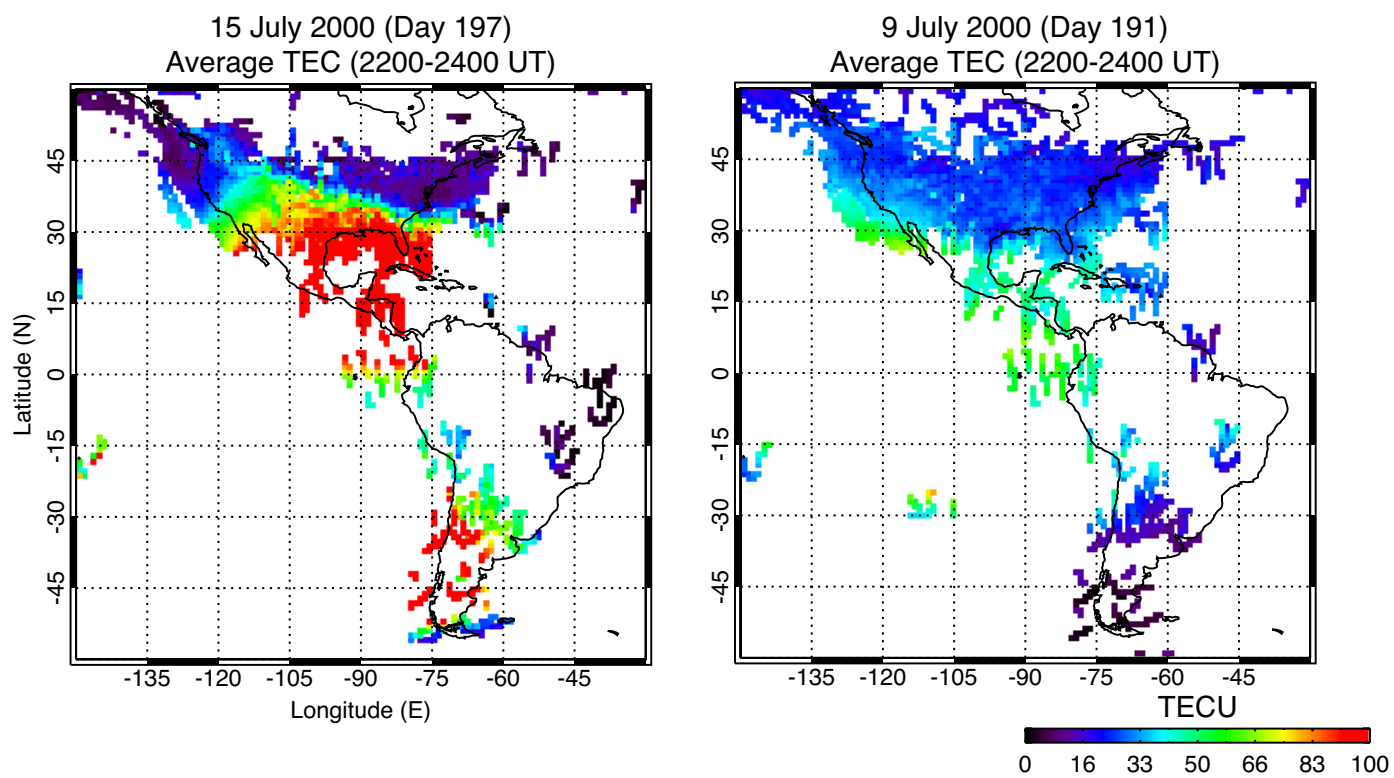

Fig. 1. GPS map of total electron content on the storm day 197 (left panel) and on a more usual quiet day 191 (right panel) of year 2000. Maps are constructed over the American continent in the period 22:00-24:00 UT. The geographic latitude and longitude are shown on each axis.

Simple numerical considerations and more sophisticated analyses have considered the relative merits of $\boldsymbol{E} \times \boldsymbol{B}$ drifts and neutral winds in producing dayside TEC enhancements (Vlasov et al., 2004; Lin et al., 2005, 2009). Observationally the afternoon TEC enhancements in the equatorial anomaly region occur at the same time as enhanced ion concentrations, called storm enhanced density or SED, are seen at middle latitudes in the afternoon and early evening, and at the same time that enhanced densities are seen in longitudinally narrow regions across North America extending from middle latitudes to the polar cusp region (Foster et al., 2005). Since the storm electric field present during these events is globally distributed, we should consider the relationships between all these features. Viewing the migration of these features as a function of universal time often shows apparent motion that leads to the hypothesis that plasma enhancements seen in one location are transported from elsewhere, as seemingly suggested by Kelley et al. (2004). Here we discuss some limitations that restrict the extent to which this might happen, and point out that changes in local loss processes, resulting from $\boldsymbol{E} \times \boldsymbol{B}$ drift motions and changes in production and loss processes produced by local composition changes in the neutral air, can produce apparent motion.

\section{Ionization transport}

We first consider the effects of enhanced upward $\boldsymbol{E} \times \boldsymbol{B}$ drifts at the equator. During quiet times the drift is upward throughout the day with average magnitudes near $15 \mathrm{~m} \mathrm{~s}^{-1}$ (Scherliess and Fejer, 1999). Thus over a period of $12 \mathrm{~h}$, plasma at the equator can be moved vertically about $650 \mathrm{~km}$. At Fregion heights the plasma remains aligned with the Earth's dipole field. Thus, any plasma created near $300-\mathrm{km}$ altitude by photoionization at the equator can move, under the action of $\boldsymbol{E} \times \boldsymbol{B}$ drift and diffusion along the magnetic field, to magnetic latitudes near $17^{\circ}$ corresponding to the footpoint at $300 \mathrm{~km}$, of the dipole magnetic field traced from $950-\mathrm{km}$ apex height.

Storm perturbations can enhance the vertical ion drift to values exceeding $100 \mathrm{~m} \mathrm{~s}^{-1}$, but drifts of this magnitude are usually short-lived with durations less than $2 \mathrm{~h}$ (Lin et al., 2005; Fejer et al., 2007). However, in these cases plasma at the magnetic equator can be moved vertically an additional $750 \mathrm{~km}$. When such motions occur near the dusk terminator they are consistent with the F-peak observed above the altitude of the DMSP satellite as reported by Basu et al. (2001), but cannot transport plasma in the F-region to magnetic latitudes beyond about 25 degrees. The work of Mannucci et al. (2006) shows quiet-day TEC at the equator near 50 units with middle latitude values near 30 units of $10^{16} \mathrm{~m}^{-2}$. Even if the entire plasma content at the equator were transported without loss to middle latitudes, it is not possible to account for TEC enhancements to 200 and sometimes 300 units. The most important property of the so-called "super-fountain" is not the greater speed of the plasma drifts, but rather the extension in latitude of the vertical and field-aligned motions of plasma during the daytime. This allows the normal content in the anomaly and beyond to be moved upward and poleward while being replaced beneath by local photoionization At middle and high latitudes uplifts produced by $\boldsymbol{E} \times \boldsymbol{B}$ 
drifts are also associated with largely horizontal transport due to the finite magnetic inclination. But an $\boldsymbol{E} \times \boldsymbol{B}$ drift of $100 \mathrm{~m} \mathrm{~s}^{-1}$ with a dip angle of 45 degrees transports plasma about 2.3 degrees per hour. Thus TEC enhancements at latitudes beyond 25 degrees cannot generally be attributed to transport from the equator. Rather, upward plasma motions in the presence of solar production act locally (within 5 degrees latitude) to increase TEC significantly by raising the existing plasma to a region of lower plasma loss rate while additional ionization is produced below.

Near the equator such uplifts are only possible through $\boldsymbol{E} \times \boldsymbol{B}$ drifts, the uplifted plasma being then transported poleward by diffusion along the magnetic field. At mid-latitudes $\boldsymbol{E} \times \boldsymbol{B}$ drifts are less effective because the upward transport is opposed by downward diffusion along the magnetic field. But equatorward meridional winds in the presence of solar production can also lead to increases in TEC (Lin et al., 2005). Additionally, at middle latitudes, neutral composition changes propagating from high latitudes may modify the local production and loss processes. The relative roles of equatorward neutral winds, $\boldsymbol{E} \times \boldsymbol{B}$ drifts and changes in neutral atmosphere composition may be different for different storms and different parts of the solar cycle, but in any case upward vertical transport of ionization in sunlight is required for significant increases of TEC to be produced.

During large magnetic storms enhancements in TEC and topside ion density are seen across the entire afternoon and evening sectors, extending up to latitudes just equatorward of the diffuse auroral zone. The sub-auroral features called storm enhanced density (SED) are frequently observed to be moving sunward and poleward toward the "noon cusp" (Foster et al., 2004). Indeed Foster et al. (2002) have shown remarkable correlation between the poleward extended features in the ionosphere and plasmaspheric enhancements imaged in the equatorial plane. The connection between a longitudinally confined region of enhanced density, moving poleward, and a reservoir of storm-enhanced density at low latitudes makes the idea of transport from the reservoir to higher latitudes a natural candidate for the explanation of such a feature. However, it is necessary to consider the lifetime of a plasma packet initially residing near 40 degrees magnetic latitude as it convects sunward and poleward. Most observations of longitudinally confined, latitudinally extended, density enhancements are seen in the afternoon sector. Even with a poleward velocity of $100 \mathrm{~m} \mathrm{~s}^{-1}$, the convection time from 40 degrees magnetic latitude to the cusp at say 75 degrees magnetic latitude is over $9 \mathrm{~h}$. This time is much longer than the lifetime against recombination of the plasma, normally of order $1 \mathrm{~h}$, so a plasma packet must be continually refreshed by new photo-production. Moreover, in the absence of static electric field configuration for which the net zonal flow is zero over a wide latitude range, the change in local time produced by the Earth's rotation will dominate the observed plasma distribution. A more likely explanation lies in a latitudinally extended enhancement in
TEC that is produced everywhere along the convective trajectory over much shorter time scales. This implies that any local enhancements require locally increased production/loss ratios due to upward drifts in the presence of sunlight and/or increases in atomic/molecular ratios in the neutral air, associated with a vertical wind in the complex patterns of stormdriven neutral winds.

The evolution of the global electric field during storm times is also responsible for the erosion of the outer plasmasphere (Chen and Grebowsky, 1974; Goldstein et al., 2003). However, there is little evidence that the optical intensity in the plume is elevated above that identified by the plasmasphere itself. Additionally, the optical intensity of the socalled plasmaspheric plumes decreases significantly as they proceed toward the dayside and there is only a very weak relationship between this optical intensity projected to the equatorial plane and the TEC below $1000 \mathrm{~km}$ altitude. Thus the evidence that the high plasma content of flux tubes moving toward the pole results from transport from the late afternoon/ evening sector may need further examination. A more likely explanation may again appear by recognizing that small poleward convection velocities in sunlight act to reduce the local plasma loss rate and locally enhance the plasma density. Recently Heelis et al. (2009) have pursued this idea to investigate the apparent longitudinal confinement of the density enhancements.

\section{Advection}

In addition to changes in plasma density produced by transport, Vlasov et al. (2003) suggested that a spatial gradient in the plasma flow may also change the plasma density. Kelley et al. (2004) extend this idea using a one-dimensional equation for the zonal variation of electron density across the terminator to explain enhancements in the plasma density at middle latitudes in the late afternoon and evening. Their equation includes only the westward ion drift measured by the ROCSAT-1 satellite (Basu et al., 2001), which decreases with increasing local time on the still sunlit afternoon side. This idea invokes a "plasma pile-up" resulting from the gradient in the measured zonal drift, which on its own would compress the plasma.

In this regard it is instructive to recall the previous work of Rishbeth and Hanson (1974) to note that the $\boldsymbol{E} \times \boldsymbol{B}$ drift motion of plasma in the F-region can only change the plasma number density along the convective path to the extent that a plasma packet moves into a region of higher or lower magnetic flux density. In a dipole field, over typical convective distances, the changes in density produced by this process are quite small. This is especially true for zonal drifts at middle latitudes, for which the magnetic flux density along the convective path does not change significantly. Thus gradients in the zonal ion drift cannot change the ion density, as apparently suggested by Kelley et al. (2004), but must 
be accompanied by corresponding changes in the meridional drift to ensure that the electric field is curl-free. Compressing the plasma perpendicular to the magnetic field is not possible with a curl-free electrostatic field and cannot create a spatial gradient in the ion density or the TEC.

\section{The Bastille stormed: discussion and conclusions}

The generation and re-distribution of plasma in the ionosphere during major storms are dramatic phenomena with large deleterious impacts on critical communication and navigation systems. The changes in the ionosphere are induced by the imposition of electric fields from the magnetosphere, modified by the changed ionospheric conductivity. The modified transport properties locally change the effective loss rate of the plasma, and in sunlight cause significant enhancements in topside electron density and TEC. We conclude that local production and loss play a dominant role and that no "compression effects" perpendicular to the magnetic field are important.

We expect $\boldsymbol{E} \times \boldsymbol{B}$ drift motions to be magnetically conjugate but the appearance of enhancements in TEC also depends on the solar zenith angle. Thus hemispherical symmetries in the convective flows may not be reflected in similar symmetries in the plasma density. In addition the observed asymmetries in plasma density are seasonally dependent. Further conjugate observations of both drift velocities (electric fields) and electron content in the afternoon local time period are required to describe and resolve these issues.

Whenever plasma transport is invoked to explain an ionospheric phenomenon, one must ask: Can the plasma travel far enough in its lifetime to produce the observed effect? Detailed modeling is needed to settle this question, but in some cases the time required is so long that changes in local time and in the imposed electric field pattern become the dominant consideration. With these considerations, a longitudinally confined, latitudinally extended, TEC enhancement at middle latitudes, such as is observed during superstorm events, would require a similar configuration in the electric field. Evidence for this feature, how it is formed and how it evolves during a storm epoch also represent some key challenges to our understanding.

\section{Postscript}

We are extremely sad that Henry Rishbeth was unable to see the final step in this research work. Regrettably, he passed away just three weeks before its acceptance. But upon reading this manuscript, or even the title, the indelible mark of Henry can be easily seen. An inspection of the reference list will show that there are many scientists that have inspired the discussion in this paper. However, Henry's ability to break down the problem into its important components is a major feature of this work. To work with Henry is to be exposed to the fundamental physical principles of our discipline and to recognize how much can be learned by applying these principles. Indeed, Henry's contributions to our field are numerous but all contain perspectives that were obtained through many years of sound thinking and reasoned analysis. From his earliest work, and the production of the timeless text "Introduction to Ionospheric Physics", his much-quoted seminal contribution on polarization electric fields in the F-region by neutral winds, to his later contributions on what continue to be ionospheric anomalies, the contributions of Henry Rishbeth will represent a lasting, accessible legacy to our field. What we have lost is his indomitable spirit, his humanity, his sense of humor and his example to make the best of any circumstance you find yourself in. We have lost a gentle giant in the field and we will miss him greatly.

Acknowledgements. This work is supported at the University of Texas at Dallas by NASA grant NNX07AF36G, at the University of Illinois by NSF grant NSF-06-44654 and at Boston College by ONR grant N00014-09-1-0432.

Topical Editor K. Kauristie thanks A. D. Richmond and another anonymous referee for their help in evaluating this paper.

\section{References}

Basu, S., Basu, S., Groves, K. M., Yeh, H.-C., Su, S.-Y., Rich, F. J., Sultan, P. J., and Keskinen, M. J.: Response of the equatorial ionosphere in the South Atlantic Region to the Great Magnetic Storm of July 15, 2000, Geophys. Res. Lett., 28(18), 3577-3580, 2001.

Basu, S., Basu, Su., Rich, F. J., Groves, K. M., MacKenzie, E., Coker, C., Sahai, Y., Fagundes, P. R., and Becker-Guedes, F.: Response of the equatorial ionosphere at dusk to penetration electric fields during intense magnetic storms, J. Geophys. Res., 112, A08308, doi:10.1029/2006JA012192, 2007.

Chen, A. J. and Grebowsky, J. M.: Plasma tail interpretations of pronounced detached plasma regions measured by OGO 5 , J. Geophys. Res., 79, 3851-3855, 1974.

Fejer, B. G., Jensen, J. W., Kikuchi, T., Abdu, M. A., and Chau, J. L.: Equatorial ionospheric electric fields during the November 2004 magnetic storm, J. Geophys Res., 112, A10304, doi:10.1029/2007JA012376, 2007.

Foster, J. C., Erickson, P. J., Coster, A. J., Goldstein, J., and Rich, F. J.: Ionospheric signatures of plasmaspheric tails, Geophys. Res. Lett., 29(13), 1623, doi:10.1029/2002GL015067, 2002.

Foster, J. C., Coster, A. J., Erickson, P. J., Rich, F. J., and Sandel, B. R.: Stormtime observations of the flux of plasmaspheric ions to the dayside cusp/magnetopause, Geophys. Res. Lett., 31, L08809, doi:10.1029/2004GL020082, 2004.

Foster, J. C., Coster, A. J., Erikson, P. J., et al.: Multiradar observations of the polar tongue of ionization, J. Geophys. Res., 110, A09S31, doi:10.1029/2004JA010928, 2005.

Goldstein, J., Sandel, B. R., Forrester, W. T., and Reiff, P. H.: IMFdriven plasmasphere erosion of 10 July 2000, Geophys. Res. Lett., 30(3), 1146, doi:10.1029/2002GL016478, 2003.

Heelis, R. A. and Coley, W. R.: Variations in the low- and middle-latitude topside ion concentration observed by DMSP 
during superstorm events, J. Geophys. Res., 112, A08310, doi:10.1029/2007JA012326, 2007.

Heelis, R. A., Sojka, J. J., David, M., and Schunk, R. W.: Storm time density enhancements in the middlelatitude dayside ionosphere, J. Geophys. Res., 114, A03315, doi:10.1029/2008JA013690, 2009.

Immel, T. J., Foster, J. C., Coster, A. J., Mende, S. B., and Frey, H. U.: Global storm time plasma redistribution imaged from the ground and space, Geophys. Res. Lett., 32, L03107, doi:10.1029/2004GL021120, 2005.

Kelley, M. C., Vlasov, M. N., Foster, J. C., and Coster, A. J.: A quantitative explanation for the phenomenon known as storm-enhanced density, Geophys. Res. Lett., 31, L19809, doi:10.1029/2004GL020875, 2004.

Kil, H., Paxton, L. J., Pi, X., Hairston, M. R., and Zhang, Y.: Case study of the 15 July 2000 magnetic storm effects on the ionosphere-driver of the positive ionospheric storm in the winter hemisphere, J. Geophys. Res., 108(A11), 1391, doi:10.1029/2002JA009782, 2003.

Lin, C. H., Richmond, A. D., Heelis, R. A., Bailey, G. J., Lu, G., Liu, J. Y., Yeh, H. C., and Su, S.-Y.: Theoretical study of the low- and midlatitude ionospheric electron density enhancement during the October 2003 superstorm: Relative importance of the neutral wind and the electric field, J. Geophys. Res., 110, A12312, doi:10.1029/2005JA011304, 2005.
Lin, C. H., Richmond, A. D., Liu, J. Y., Bailey, G. J., and Reinisch, B. W.: Theoretical study of new plasma structures in the lowlatitude ionosphere during a major magnetic storm, J. Geophys. Res., 114, A05303, doi:10.1029/2008JA013951, 2009.

Mannucci, A. J., Tsurutani, B. T., Iijima, B. A., Komjathy, A., Saito, A., Gonzalez, W. D., Guarnieri, F. L., Kozyra, J. U., and Skoug, R.: Dayside global ionospheric response to the major interplanetary events of October 29-30, 2003 "Halloween Storms", Geophys. Res. Lett., 32, L12S02, doi:10.1029/2004GL021467, 2005.

Rishbeth, H. and Hanson, W. B.: A comment on 'plasma pile-up' in the F-region, J. Atmos. Terr. Phys., 36, 703-706, 1974.

Scherliess, L. and Fejer, B. G.: Radar and satellite global equatorial $F$ region vertical drift model, J. Geophys. Res., 104(A4), 68296842, 1999.

Tsurutani, B., Mannucci, A., Iijima, B., et al.: Global dayside ionospheric uplift and enhancement associated with interplanetary electric fields, J. Geophys. Res., 109, A08302, doi:10.1029/2003JA010342, 2004.

Vlasov, M., Kelley, M. C., and Kil, H.: Analysis of ground-based and satellite observations of F-region behaviour during the great magnetic storm of July 15, 2000, J. Atmos. Solar-Terrest. Phys., 65, 1223-1234, 2003.

Yin, P., Mitchell, C. N., Spencer, P. S. J., and Foster, J. C.: Ionospheric electron concentration imaging using GPS over the USA during the storm of July 2000, Geophys. Res. Lett., 31, L12806, doi:10.1029/2004GL019899, 2004. 